\title{
YAGG:Ce transparent ceramics with high luminous efficiency for solid-state lighting application
}

\author{
Hui HUA ${ }^{a, b, \dagger}$, Shaowei FENG ${ }^{a, b, \dagger}$, Zhongyu OUYANG ${ }^{c}$, Hezhu SHAO ${ }^{b}$, \\ Haiming QIN ${ }^{b, *}$, Hui DING ${ }^{b}$, Qiping DU ${ }^{a, b}$, Zhijun ZHANG ${ }^{a, *}$, \\ Jun JIANG ${ }^{b, *}$, Haochuan JIANG ${ }^{b}$ \\ ${ }^{a}$ School of Materials Science and Engineering, Shanghai University, Shanghai 200072, China \\ ${ }^{b}$ Ningbo Institute of Materials Technology and Engineering, Chinese Academy of Sciences, Ningbo 315201, China \\ ${ }^{c}$ School of Materials Science and Engineering, Tianjin University, Tianjin 300072, China
}

Received: November 23, 2018; Revised: January 23, 2019; Accepted: February 9, 2019

(C) The Author(s) 2019.

\begin{abstract}
A series of $\mathrm{Y}_{2.985} \mathrm{Al}_{5-x} \mathrm{Ga}_{x} \mathrm{O}_{12}: 0.015 \mathrm{Ce}$ (YAGG:Ce, $\left.x=0,1,2,3,4,5\right)$ transparent ceramics were prepared via a solid-state reaction method. Two-step sintering technique was proved to be an effective approach to prepare functional ceramics with high Ga concentration, and $\mathrm{Y}_{3} \mathrm{Ga}_{5} \mathrm{O}_{12}$ (YGG) transparent ceramic was successfully prepared for the first time. According to the variation of $\mathrm{Al} / \mathrm{Ga}$ ratio, regulation of band structure and luminescence properties of YAGG:Ce transparent ceramics were effectively investigated. When Ga substitutes Al sites, the tetrahedral site is more favorable compared to the octahedral site for Ga to occupy according to the first-principle calculation. A continuous blue shift of the emission from 565 to $515 \mathrm{~nm}$ was achieved as Ga was gradually introduced into $\mathrm{Y}_{3} \mathrm{Al}_{5} \mathrm{O}_{12}$ : Ce matrix. High quality green light was obtained by coupling the YAGG:Ce ceramics with commercial blue InGaN chips. Transparent luminescence ceramics accomplished in this work can be quite prospective for high power LED application.
\end{abstract}

Keywords: YAGG:Ce transparent ceramics; two-step sintering; $\mathrm{Al} / \mathrm{Ga}$ ratio; luminous efficiency; green-emitting LEDs

\section{Introduction}

Light-emitting diodes (LEDs) have been rapidly developed in the field of display and illumination due to their high luminous efficiency, long lifetime, and low energy consumption [1-4]. Commercial LEDs normally

$\uparrow$ These authors contributed equally to this work.

* Corresponding authors.

E-mail: H. Qin, qinhaiming@nimte.ac.cn;

Z. Zhang, zhangzhijun@shu.edu.cn;

J. Jiang, jjun@nimte.ac.cn use a blue InGaN chip exciting luminescent materials such as yellow-emitting $\mathrm{Y}_{3} \mathrm{Al}_{5} \mathrm{O}_{12}$ : $\mathrm{Ce}$ (YAG:Ce) to generate white light $[5,6]$. However, its main drawback is low color rendering index (CRI) due to the deficiency of red spectral region $[7,8]$. At the same time, LEDs which emit pure green or red light were intensively studied in order to obtain high quality color display or combined white light $[9,10]$. In recent years, nitride red phosphors with excellent luminescence properties such as $\mathrm{M}_{2} \mathrm{Si}_{5} \mathrm{~N}_{8}(\mathrm{M}=\mathrm{Ba}, \mathrm{Sr})$ [11,12] and $\mathrm{CaAlSiN}_{3}$ [13] have been widely investigated, while accomplishment of green-emitting luminescent materials with outstanding 
luminescence performance still remains the challenge.

Green-emitting luminescent materials play vital role in color display application such as pc-LEDs and combined white LEDs with RGB primary colors $[14,15]$. Currently, green-emitting luminescent materials mainly include $\mathrm{Ce}^{3+}, \mathrm{Eu}^{2+}$, and $\mathrm{Tb}^{3+}$ activated phosphors, such as $\mathrm{Ca}_{3} \mathrm{Sc}_{2} \mathrm{Si}_{3} \mathrm{O}_{12}: \mathrm{Ce}^{3+}$ [16], $\mathrm{Ba}_{2} \mathrm{MgSi}_{2} \mathrm{O}_{7}: \mathrm{Eu}^{2+}$ [17], $\mathrm{SrSi}_{2} \mathrm{O}_{2} \mathrm{~N}_{2}: \mathrm{Eu}^{2+}$ [18], and $\mathrm{NaCaPO}_{4}: \mathrm{Tb}^{3+}$ [19]. For example, $\mathrm{Ba}_{2} \mathrm{MgSi}_{2} \mathrm{O}_{7}: \mathrm{Eu}^{2+}$ has been investigated by Zhang et al. [17] as a green-emitting phosphor for pc-LEDs. $\mathrm{SrSi}_{2} \mathrm{O}_{2} \mathrm{~N}_{2}: \mathrm{Eu}^{2+}$ obtains high quality emission spectrum in the green light region around $540 \mathrm{~nm}$ when excited by UV-visible (300-460 nm) light $[18,20]$. Those fluorescent materials have the advantages of wide excitation and emission spectra, as well as high CRI. However, the preparation conditions of silicon-based nitrogen (oxygen) green phosphors are demanding [21]. What is more important, phosphors involved solid-state lighting devices suffer the disadvantage of low thermal conductivity, which limits their application in high-power areas [22]. Transparent ceramics were reported as novel luminescent materials due to their favorable physical and luminescence properties $[23,24]$. Luminescent ceramics build much higher thermal conductivity compared to that of epoxy packaged phosphors (always $<1 \mathrm{~W} /(\mathrm{m} \cdot \mathrm{K})$ ). Ce-doped garnet is a promising material for green-emitting luminescent matrix [25], such as $\mathrm{Lu}_{3} \mathrm{Al}_{5} \mathrm{O}_{12}: \mathrm{Ce}$ (LuAG:Ce). However, LuAG:Ce involves element $\mathrm{Lu}$, which causes high cost of this material. Therefore, researchers accommodate different cations in garnet crystalline structure to adjust its band structure and luminescence properties in order to obtain high quality green-emitting luminescent ceramics with lower cost [26]. Among them, $\mathrm{Y}_{3} \mathrm{Al}_{5-x} \mathrm{Ga}_{x} \mathrm{O}_{12}$ (YAGG) emerged as a promising matrix for green-emitting luminescent ceramics. Mori et al. [27] investigated photoluminescence $(\mathrm{PL})$ and scintillation properties of $\mathrm{Ce}^{3+}$-doped $\mathrm{Y}_{3} \mathrm{Al}_{2} \mathrm{Ga}_{3} \mathrm{O}_{12}$ (YAGG:Ce) transparent ceramics synthesized by vacuum sintering with different $\mathrm{Ce}^{3+}$ concentrations from 0.3 to $1 \mathrm{~mol} \%$, and the transmittance could reach around $50 \%-70 \%$ over $500 \mathrm{~nm}$. Ueda [28] prepared a series of YAGG:Ce ceramics, which are able to emit adjustable green light via the variation of Ga concentration. Xu et al. [29] developed rare earth doped YAGG persistent phosphors with orange and light green persistent luminescence, based on the knowledge of the energy level diagram of lanthanide dopants. More importantly, cost of YAGG is much lower than that of LuAG. Thermal conductivity of YAGG:Ce luminescent material is between 9 and $14 \mathrm{~W} / \mathrm{m} \cdot \mathrm{K}$ [30], which is much higher than that of other green-emitting phosphors.

However, controllable preparation of YAGG:Ce luminescent ceramics remains a great challenge due to the evaporation of $\mathrm{Ga}$ at high temperature. Conventional sintering method such as vacuum sintering requires high temperature around $1700{ }^{\circ} \mathrm{C}$ [30] with long holding time; moreover, it is easy for Ga to evaporate at high temperature when its concentration is high $[31,32]$, which makes the controllable preparation of YAGG:Ce transparent ceramics even difficult. And successful preparation of $\mathrm{Y}_{3} \mathrm{Ga}_{5} \mathrm{O}_{12}$ (YGG) transparent ceramics has not yet been reported. In this study, we prepared a series of YAGG:Ce transparent ceramics via a solidstate reaction two-step sintering technique. Ga dependent luminescence and thermal properties of as prepared YAGG:Ce transparent ceramics were systematically investigated. Two-step sintering technique was proved to be an effective approach to prepare Ga involved ceramics. YGG transparent ceramic was successfully prepared, which can offer scientists new ceramic matrix to explore luminescent materials. High quality green light was obtained by coupling the YAGG:Ce ceramics with commercial blue LED chips. Transparent luminescent ceramics accomplished in this work can be quite prospective for high power green-emitting LED application.

\section{Experimental and calculation methods}

\section{1 Experimental methods}

A series of $\mathrm{Y}_{2.985} \mathrm{Al}_{5-x} \mathrm{Ga}_{x} \mathrm{O}_{12}: 0.015 \mathrm{Ce}(x=0,1,2,3,4$, $5)$ polycrystalline ceramics were prepared using a solid-state reaction method. Commercial $\mathrm{Al}_{2} \mathrm{O}_{3}(99.99 \%$, Taimei Chemistry Co., Ltd., Japan), $\mathrm{Y}_{2} \mathrm{O}_{3}(99.9 \%$, Rare-chem Hi-tach Co., Ltd., China), $\mathrm{Ga}_{2} \mathrm{O}_{3}(99.9 \%$, Chalco Henan Aluminum Fabrication Co., Ltd., China), and $\mathrm{CeO}_{2}$ (99.9\%, Beijing Dk Nano Technology Co., Ltd., China) were used as raw materials. The starting powders were mixed by ball-milling machine with $\mathrm{ZrO}_{2}$ balls and ethanol for $10 \mathrm{~h}$. Mixed powders were dried at $80{ }^{\circ} \mathrm{C}$ for $12 \mathrm{~h}$ to remove ethanol solvent. Dried powders were pressed into $25 \mathrm{~mm}$ diameter pellets under pressure of $250 \mathrm{MPa}$. The pellets were sintered at $1550{ }^{\circ} \mathrm{C}$ in flowing oxygen atmosphere for $2 \mathrm{~h}$ and then sintered in hot isostatic pressing (HIP) equipment at $1500{ }^{\circ} \mathrm{C}$ for $2 \mathrm{~h}$. Finally, as-prepared 
specimens were mirror polished on both sides for characterization.

\section{2 Characterization}

Phase composition of the ceramics was characterized by X-ray diffraction (XRD, Model D8 Advance, Bruker AXS Co., Ltd., Germany), using $\mathrm{Cu} \mathrm{K} \alpha$ radiation $(1.5406 \AA)$ over the range of $2 \theta=10^{\circ}-90^{\circ}$, and the XRD scan speed is $0.02 \mathrm{step} / \mathrm{s}$. Surface morphologies were characterized by scanning electron microscopy (SEM, Quanta FEG 250, FEI Co., Ltd., USA). In-line transmittance spectra were tested using an UV/Vis/NIR spectrophotometer (Lambda 950, Perkin Elmer Co., Ltd., USA) over the wavelength range of 250-800 nm. PL and photoluminescence excitation (PLE) spectra were measured at room temperature using a fluorescence spectrophotometer (F-4600, Hitachi, Tokyo, Japan). Commission International de L'Eclairage chromaticity coordinates and color rendering index were measured by an integrating sphere (PMS-50, Everfine, China) under a forward bias of $300 \mathrm{~mA}$. The internal and external QEs were measured by a QE-2100 spectrophotometer from Otsuka Photal Electronics. The fluorescence lifetime of $\mathrm{Ce}^{3+}$ was measured by using the spectrometer FL-311 (Horiba Fluorolog) pumped by a Nano LED lamp with time of $1 \mathrm{~ns}$.

\section{3 Calculation methods}

For the calculations of energy of $\mathrm{Y}_{3} \mathrm{Al}_{5-x} \mathrm{Ga}_{x} \mathrm{O}_{12}$ with $x=$ 0.25 , the calculations are based on density functional theory method in the generalized gradient approximation (GGA) and performed with the Perdew-Burke-Ernzerhof (PBE) functional [33] as implemented in the VASP code, which employs a plane-wave basis [34,35]. The plane-wave energy cut-off is set to be $520.00 \mathrm{eV}$, and the electronic energy convergence is $10^{-5} \mathrm{eV}$. During

relaxations, the force convergence for ions is $10^{-2} \mathrm{eV} / \AA$. And a $\Gamma$-centered $3 \times 3 \times 3$ Monkhorst-Pack k-point mesh is used to sample the irreducible Brillouin zone.

\section{Results and discussion}

Figure 1 shows the picture of as-prepared YAGG:Ce transparent ceramics with different $\mathrm{Ga}$ doping concentration. All samples are $1 \mathrm{~mm}$ in thickness. It can be seen that all ceramics obtain good transparency. With increasing Ga concentration, the body color of the samples varies from yellow to greenish yellow.

Figure 2(a) displays the XRD patterns of different YAGG:Ce ceramics. It can be seen from Fig. 2 that all diffraction peaks of samples $x=0$ and $x=5$ match well with the standard diffraction data of $\mathrm{Y}_{3} \mathrm{Al}_{5} \mathrm{O}_{12}$ (JCPDS\#33-0040) and $\mathrm{Y}_{3} \mathrm{Ga}_{5} \mathrm{O}_{12}$ (JCPDS\#71-2151), respectively. No other diffraction peaks were observed. It indicates that pure YAG and YGG crystalline structures were obtained in samples $x=0$ and $x=5$, respectively. As Ga content increases, diffraction patterns of different ceramics are similar with no extra diffraction peaks observed. However, all diffraction peaks shift to lower angle with increasing Ga concentration (Fig. 2(b)), indicating the expansion of the unit cell. Calculated lattice constants of each sample from their XRD patterns are shown in Fig. 2(c). The lattice constant increases linearly with increasing Ga content. That phenomenon

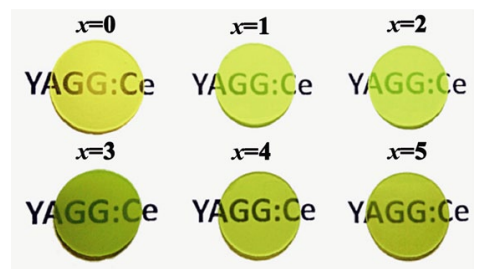

Fig. 1 Pictures of $\mathrm{Y}_{3} \mathrm{Al}_{5-x} \mathrm{Ga}_{x} \mathrm{O}_{12}$ : $\mathrm{Ce}(x=0-5)$ ceramics.
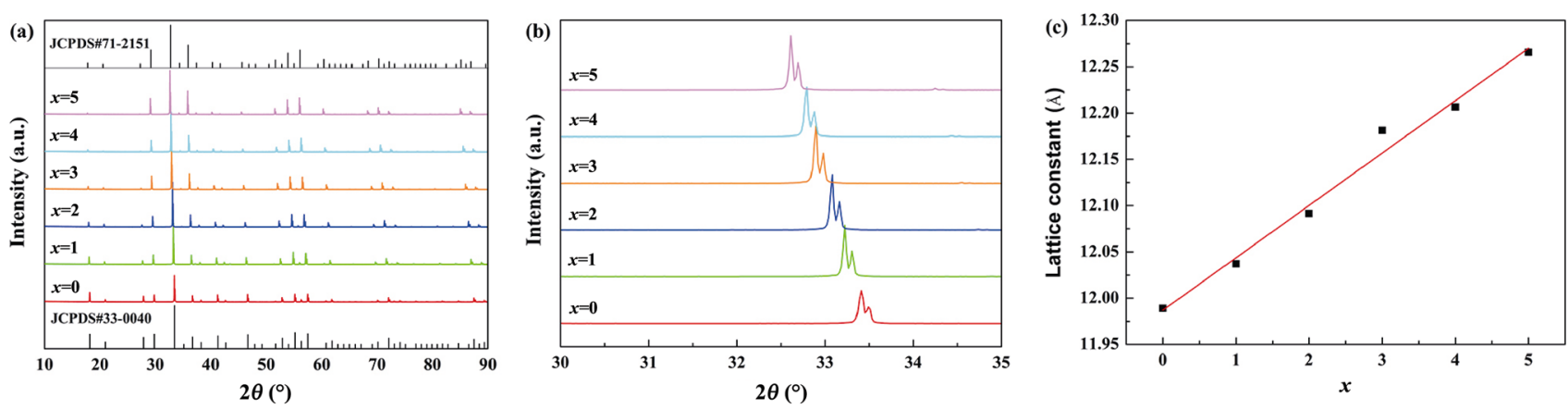

Fig. 2 (a) XRD patterns of $\mathrm{Y}_{3} \mathrm{Al}_{5-x} \mathrm{Ga}_{x} \mathrm{O}_{12}$ : $\mathrm{Ce}(x=0-5)$ ceramics, (b) expanded view of the $2 \theta$ diffraction peak between $30^{\circ}$ and $35^{\circ}$, and (c) calculated lattice constants from XRD diffraction data. 
follows the Vegard's law against Ga content, which can be attributed to the fact that ionic radius of $\mathrm{Ga}^{3+}$ ion $(0.62 \mathrm{~nm})$ is larger than that of $\mathrm{Al}^{3+}$ ion $(0.535 \mathrm{~nm})$ [36].

In order to better understand the effect of $\mathrm{Ga}$ concentration in YAGG:Ce ceramics on their optical properties, changes in crystalline structure of YAGG:Ce ceramics caused by different Ga concentration were analyzed. Rietveld refinements for YAG:Ce, $\mathrm{Y}_{3} \mathrm{Al}_{3} \mathrm{Ga}_{2} \mathrm{O}_{12}$ :Ce, and YGG:Ce were carried out and presented in Fig. 3. The main parameters determined with Rietveld refinements and the main bond lengths are provided in Table S1 in the Electronic Supplementary Material (ESM). Low R-factors in Table S1 in the ESM indicate that the results of Rietveld refinements are reliable. According to the refinement, $\mathrm{Ce} / \mathrm{Y}-\mathrm{O}$ bond lengths in its dodecahedron coordinated unit cell can be divided into two types, which is named $\mathrm{L}\left(\mathrm{Ce} / \mathrm{Y}-\mathrm{O}^{\prime}\right)$ (shorter bond lengths) and $\mathrm{L}\left(\mathrm{Ce} / \mathrm{Y}-\mathrm{O}^{*}\right)$ (longer bond lengths) in present work, indicating that the structure of the dodecahedron is distorted. Polyhedron distortion ratio $D$ can be quantitatively calculated using Eq. (1) [37,38]:

$$
D=(1 / n)\left[\left(L_{i}-L_{\text {av }}\right) / L_{\text {av }}\right]
$$

when the bond length change effect is solely considered, where $L_{i}$ is the distance from central cation atom to " $i$ " coordinating oxygen atom, $L_{\mathrm{av}}$ is the averaged bond length. Figure 3(d) shows $\mathrm{L}(\mathrm{Ce} / \mathrm{Y}-\mathrm{O})$ bond lengths and $\mathrm{CeO}_{8}$ polyhedron distortion with $\mathrm{Ga}$ concentration. $\mathrm{L}\left(\mathrm{Ce} / \mathrm{Y}-\mathrm{O}^{\prime}\right)$ increases with increasing $\mathrm{Ga}$ concentration, while $\mathrm{L}\left(\mathrm{Ce} / \mathrm{Y}-\mathrm{O}^{*}\right)$ decreases with increasing $\mathrm{Ga}$ concentration. Polyhedron distortion ratio becomes smaller as Ga was introduced into the crystalline structure. The distortion of YAG:Ce is $2.5 \%$, while that is decreased to $1.89 \%$ in YGG:Ce (Table S1 in the ESM). The effect of crystal structure on spectra and energy level structure will be discussed below.

Figure 4(a) shows the illustration of YAGG crystalline structure. $Y$ cation occupies the dodecahedron site, while $\mathrm{Al}$ and $\mathrm{Ga}$ can be accommodated in the tetrahedron and octahedron sites. In YAG, all tetrahedron and octahedron sites are occupied by $\mathrm{Al}$ cations. When Ga is introduced into YAG matrix, it is reasonable to expect that $\mathrm{Ga}$ occupies the sites of octahedron firstly based on conventional ionic radius arguments and theoretical calculations [39]. However, experimental studies and energies obtained by first-principles calculation have shown that the tetrahedral site is more favorable compared to the octahedral site for Ga to occupy [40,41]. To resolve above inconsistent opinions, we also performed the first-principles calculation for the $\mathrm{Y}_{3} \mathrm{Al}_{5-x} \mathrm{Ga}_{x} \mathrm{O}_{12}$ with $x=0.25$. First-principles calculation shows that
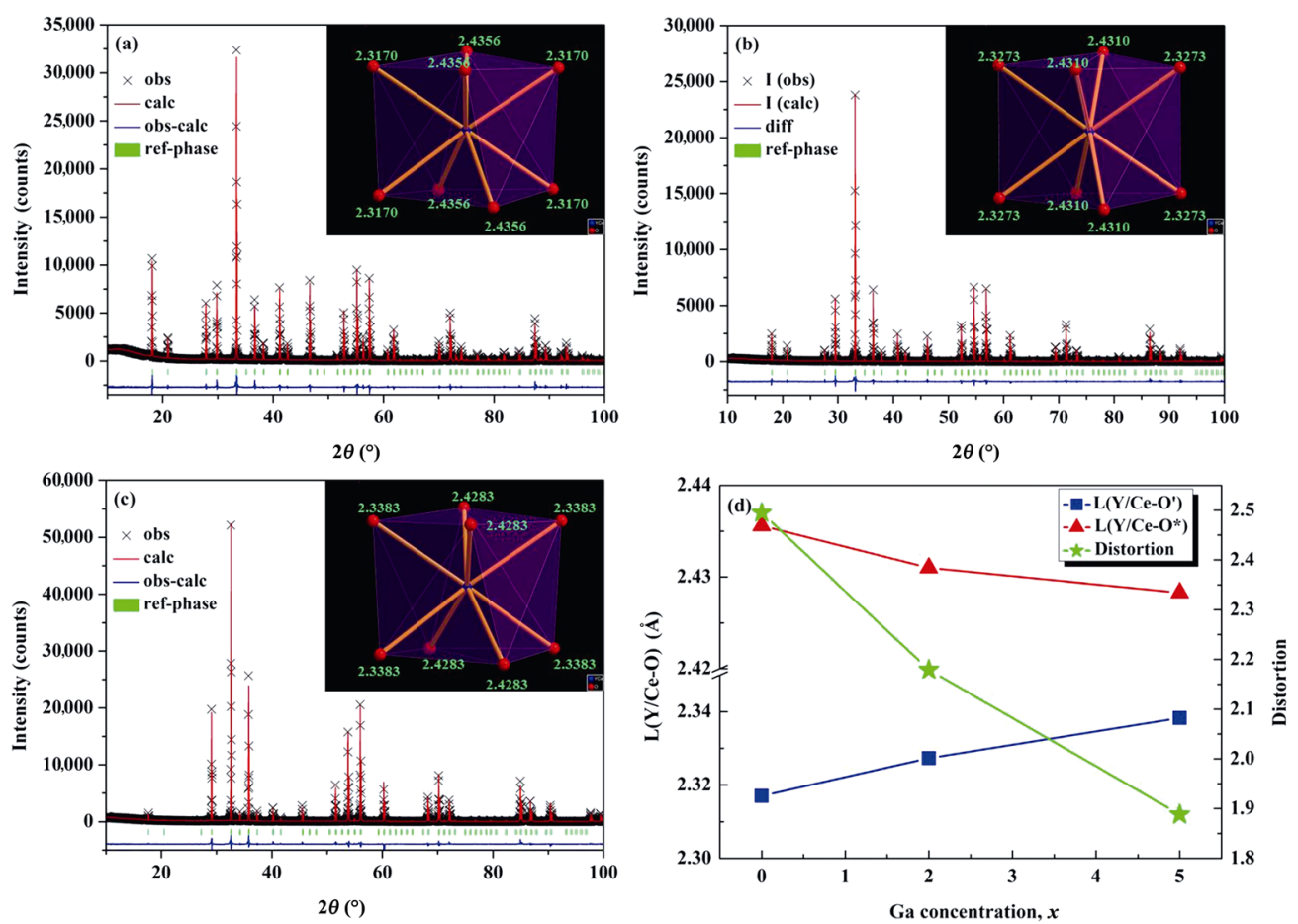

Fig. 3 Rietveld refinements for $\mathrm{Y}_{3} \mathrm{Al}_{5-x} \mathrm{Ga}_{x} \mathrm{O}_{12}$ :Ce ceramics, where $x$ is equal to (a) 0 , (b) 2, and (c) 5 . The insets are coordinate environments of $\mathrm{Ce} / \mathrm{Y}$ with oxygen atoms, (d) $\mathrm{Ce} / \mathrm{Y}-\mathrm{O}$ bond lengths and $\mathrm{CeO}_{8}$ polyhedron distortion change with $\mathrm{Ga}$ concentration. 

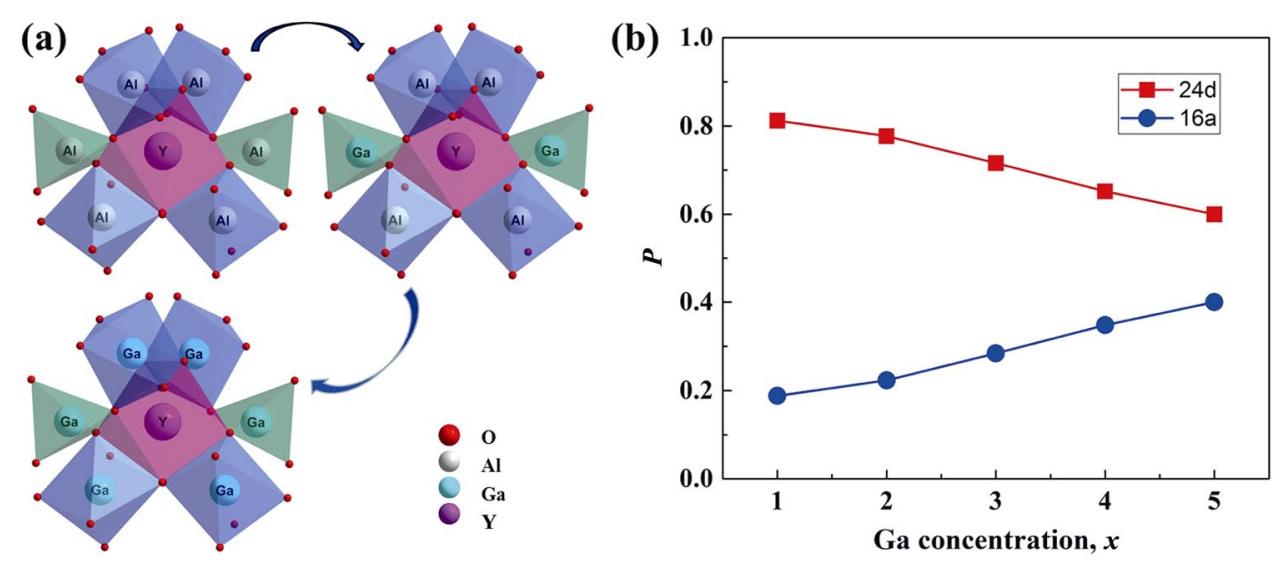

Fig. 4 (a) Illustration of YAGG crystalline structure, (b) probability of Ga ions occupying octahedral (16a) and tetrahedral (24d) sites varying with Ga content.

the energy of $\mathrm{Y}_{3} \mathrm{Al}_{5-x} \mathrm{Ga}_{x} \mathrm{O}_{12}$ as Ga occupies octahedral site is higher than that in tetrahedral site by $40 \mathrm{meV}$. This is consistent with the experimental results of Ref. [41]. According to experimental studies and Rietveld refinements, probability of Ga ions occupying octahedral (16a) and tetrahedral (24d) sites varying with Ga content is shown in Fig. 4(b). As Ga concentration increases, the proportion of $\mathrm{Ga}$ ions occupying tetrahedral sites is always larger than that of octahedral sites. It further confirms that $\mathrm{Ga}$ ions occupy tetrahedral sites first. Figure $\mathrm{S} 1$ in the ESM shows the crystal structure of $\mathrm{Y}_{3} \mathrm{Al}_{3} \mathrm{Ga}_{2} \mathrm{O}_{12}$ :Ce ceramic.

Figure 5 shows the surface morphologies of YAGG:Ce ceramics with different Ga concentration. It can be seen from the images that all ceramics obtain regular grains and clean grain boundaries. In addition, average grain size became larger with increasing Ga content, which can be determined by linear intercept method (200 grains counted). Average grain size of sample $x=1$ to $x=5$ is $3.23,5.32,6.49,8.60$, and $12.72 \mu \mathrm{m}$, respectively. It indicates that the addition of Ga can significantly affect the sintering ability and growth behavior of YAG powders. When Ga concentration is high, such as $x=4$ and $x=5$ samples, curved grain boundaries can be observed (Figs. 5(e) and 5(f)). While it can be seen from the SEM images of samples from $x=3$ to $x=5$ that there is no Ga segregation. At the same time, atomic percentage is consistent with its matrix compound component according to EDS analysis (Fig. S2 in the ESM), indicating that no second phase exists at the grain boundary. Difference of grain boundary width is mainly caused by their different sintering ability. It indicated that strong stress was remained in the grain boundaries. Faster grain growth rate and remained stress in YAGG ceramics with higher Ga concentration make the accomplishment of those ceramics challenging work via other preparation methods.

Figure 6 shows the in-line transmission spectra from

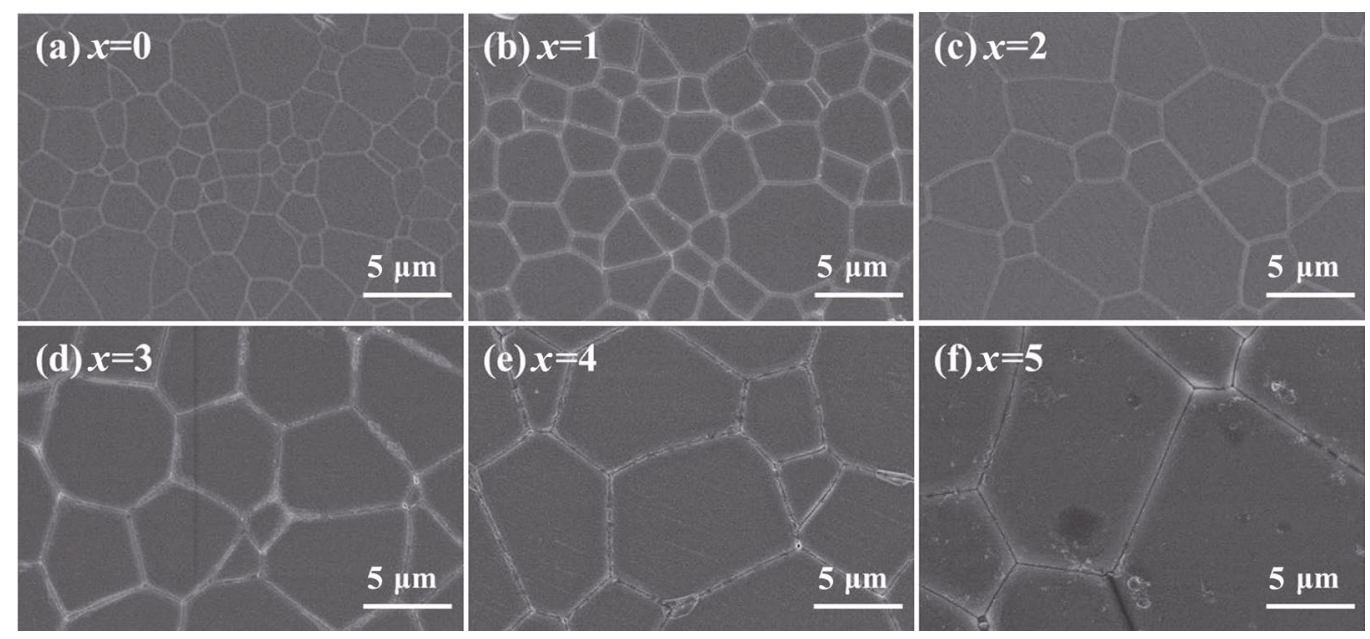

Fig. 5 SEM surface morphologies of $\mathrm{Y}_{3} \mathrm{Al}_{5-x} \mathrm{Ga}_{x} \mathrm{O}_{12}$ : $\mathrm{Ce}(x=0-5)$ ceramics. 


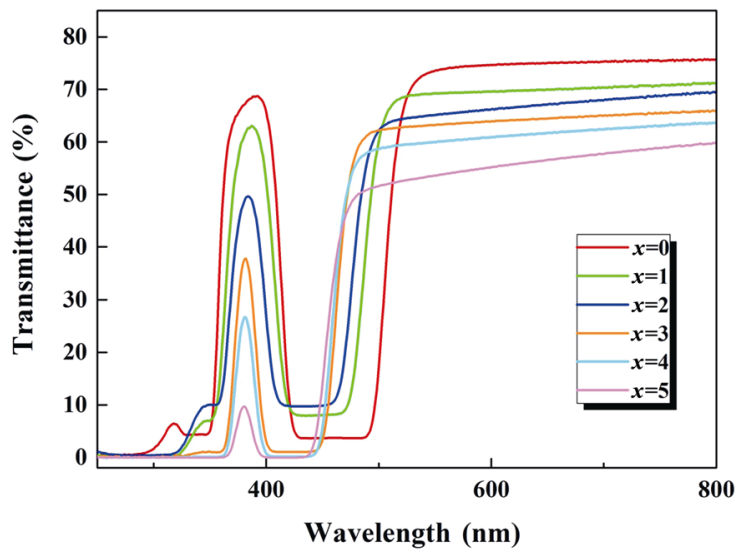

Fig. 6 Transmission spectra of $\mathrm{Y}_{3} \mathrm{Al}_{5-x} \mathrm{Ga}_{x} \mathrm{O}_{12}$ : $\mathrm{Ce}(x=$ $0-5)$ ceramics.

250 to $800 \mathrm{~nm}$ of YAGG:Ce samples. The YAG:Ce sample obtains the best transmittance. Its highest transmittance can reach $76 \%$ at the range of $500-800 \mathrm{~nm}$. With the increase of $\mathrm{Ga}$ content, the transmittance of ceramics declines gradually from $71 \%$ to $60 \%$. Those results are consistent with the results shown in Figs. 1 and 5. Wide grain boundaries and irregular crystal grains in ceramics with higher $\mathrm{Ga}$ concentration performed as scattering centers, causing the decline of their transmittance. Ceramics with higher Ga content obtain higher refractive index, increasing the reflection and consequently lowering the measured transmission. The absorption bands around $400-500 \mathrm{~nm}$ can be attributed to $4 \mathrm{f} \rightarrow 5 \mathrm{~d}_{1}$ transition of $\mathrm{Ce}^{3+}$ in garnet crystalline structure. The absorption band increases in intensity and shifts to shorter wavelengths as Ga content increases. That means the energies between $4 \mathrm{f}$ and $5 \mathrm{~d}$ increased as $\mathrm{Ga}$ was introduced into the crystal structure.

Figure 7 shows the PLE and PL spectra of different YAGG:Ce ceramics. Figure 7(a) shows that two excitation bands were observed. One is in the range of 390-550 $\mathrm{nm}$ and the other is in the range of $320-380 \mathrm{~nm}$, which can be ascribed to the transitions from the ground $4 \mathrm{f}$ level to the $5 \mathrm{~d}_{1}$ and $5 \mathrm{~d}_{2}$ of $\mathrm{Ce}^{3+}$ ions, respectively [42,43]. The excitation band at $320-380 \mathrm{~nm}$ is shifted to longer wavelength as $\mathrm{Ga}$ content increases, while excitation band at $390-550 \mathrm{~nm}$ is shifted to shorter wavelength. Thus, it can be calculated that with the increasing $\mathrm{Ga}$ concentration, $5 \mathrm{~d}_{1}$ band shifts towards a higher energy position, while $5 \mathrm{~d}_{2}$ band shifts towards the opposite direction. Splitting values of $5 \mathrm{~d}$ is decreased while energy level difference between $4 \mathrm{f}$ to $5 \mathrm{~d}$ is increased. That result is also consistent with the result shown in Fig. 6. Samples can be effectively excited by all points on the platform of $425-455 \mathrm{~nm}$, as shown in Fig. S3 in the ESM. The wide excitation platform can match better with blue light chip, which can help with the accomplishment of high luminous efficiency. Figure 7(b) depicts the normalized emission spectra of YAGG:Ce transparent ceramics. As the adding amount of $\mathrm{Ga}$ increases, a continuous blue shift of the emission spectra is observed. For the sample $x=0$, the emission peak is at $565 \mathrm{~nm}$. While the emission peak of sample $x=4$ is blue shifted to $515 \mathrm{~nm}$. Changes in PLE and PL spectra can be attributed to the crystal field environment variation around the $\mathrm{Ce}^{3+}$ ions [44]. According to the Rietveld refinement results aforementioned (Fig. 3), $\mathrm{L}(\mathrm{Ce} / \mathrm{Y}-\mathrm{O}$ ') plays major role in the crystalline field of $\mathrm{Ce}$ ions. Introduction of $\mathrm{Ga}$ cation in garnet crystalline structure leads to the increase in $\mathrm{L}(\mathrm{Ce} / \mathrm{Y}-\mathrm{O}$ ') bond lengths, resulting in weaker crystal field splitting of the $5 \mathrm{~d}$ orbital of $\mathrm{Ce}^{3+}$ and a blue-shift emission. Polyhedron distortion ratio becomes smaller with increasing $\mathrm{Ga}$. It indicates that crystal field around $\mathrm{Ce}^{3+}$ ions becomes more symmetric, which is consistent with the results

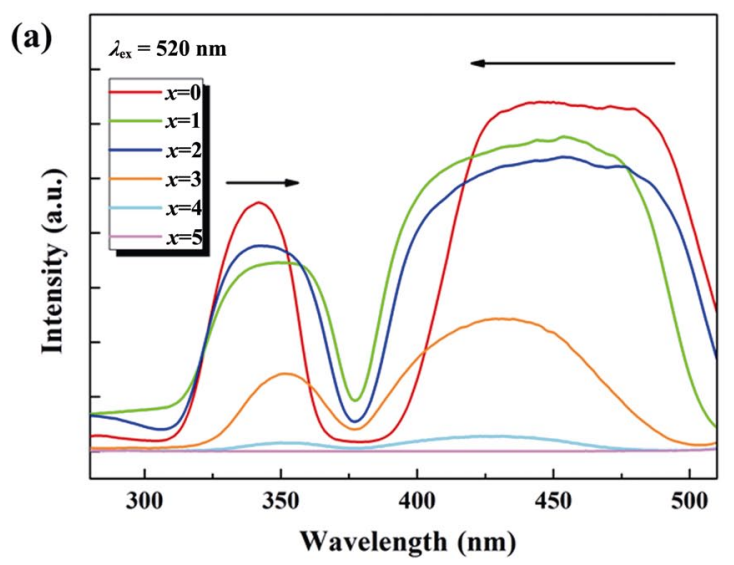

(b)

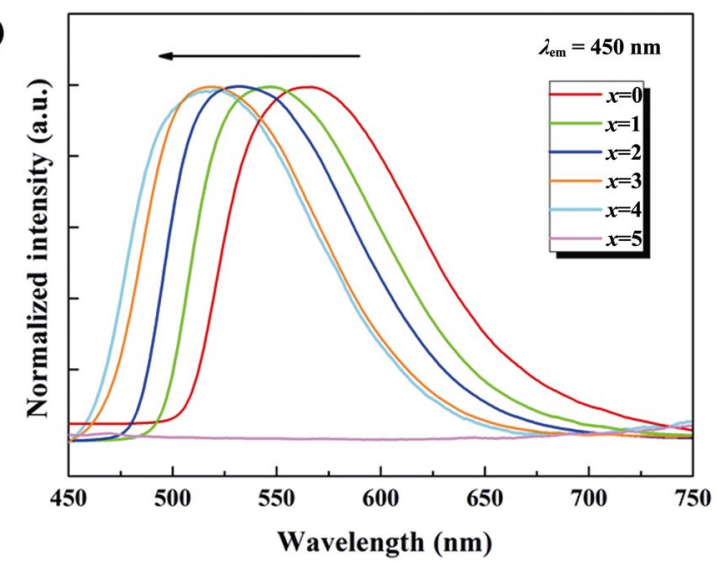

Fig. 7 PLE and PL spectra of $\mathrm{Y}_{3} \mathrm{Al}_{5-x} \mathrm{Ga}_{x} \mathrm{O}_{12}$ : $\mathrm{Ce}(x=0-5)$ ceramics. 
reported in Refs. [42,43]. As Al ions were completely replaced by $\mathrm{Ga}$ ions, no PLE or PL spectrum were observed, which can be attributed to that the $5 \mathrm{~d}$ energy levels of $\mathrm{Ce}^{3+}$ ions move into the conduction band and thus results in the luminous quenching.

Average internal quantum efficiency (IQE) and external quantum efficiency (EQE) values for $\mathrm{Y}_{3} \mathrm{Al}_{5-x} \mathrm{Ga}_{x} \mathrm{O}_{12}$ :Ce $(x=0-5)$ ceramics are shown in Fig. 8. IQE values of samples from $x=0$ to $x=5$ are $97.1 \%, 89.9 \%, 87.4 \%$, $79.1 \%, 3.9 \%$, and $1.3 \%$. While their EQE values are $80.1 \%, 44.6 \%, 39.8 \%, 34.3 \%, 2.2 \%$, and $0.7 \%$, respectively. These results indicate that the luminescence efficiency of YAGG:Ce ceramics can be extraordinary as $\mathrm{Ga}$ concentration less than $60 \%$, which makes YAGG:Ce ceramics promising green-emitting materials for LED application. Fluorescence decay curves of $\mathrm{Y}_{3} \mathrm{Al}_{5-x} \mathrm{Ga}_{x} \mathrm{O}_{12}$ : $\mathrm{Ce}(x=0-4)$ ceramics are shown in Fig. $\mathrm{S} 4$ in the ESM. Cutting off the baseline and fitting the decay curves, the average lifetime of $\mathrm{Y}_{3} \mathrm{Al}_{5-x} \mathrm{Ga}_{x} \mathrm{O}_{12}: \mathrm{Ce}$ $(x=0-4)$ ceramics is $27,14.3,12.8,11.5$, and $11.2 \mathrm{~ns}$, respectively.

Table 1 shows the color coordinates, LE, and color temperature (CCT) of the samples as we combine our ceramics with blue LED chips. LE of YAG:Ce ceramic can reach up to $124.48 \mathrm{~lm} / \mathrm{W}$, which is of an excellent performance in YAG ceramic system. As Ga is introduced into the matrix, LE of those samples declines significantly. And the LE and color coordinate for the $x=5$ LED device is just the evaluation of blue LED itself, since YGG:Ce sample did not contribute any luminescence. The CCT of the samples gradually increases from nearly 4000 to over $6000 \mathrm{~K}$, which is consistent with the rule that the color of samples changes from orange to green.

Figure 9(a) shows the chromaticity color coordinates of the ceramics. Red dots represent the color parameters of $\mathrm{Y}_{3} \mathrm{Al}_{5-x} \mathrm{Ga}_{x} \mathrm{O}_{12}$ : $\mathrm{Ce}(x=0-4)$ ceramics without the

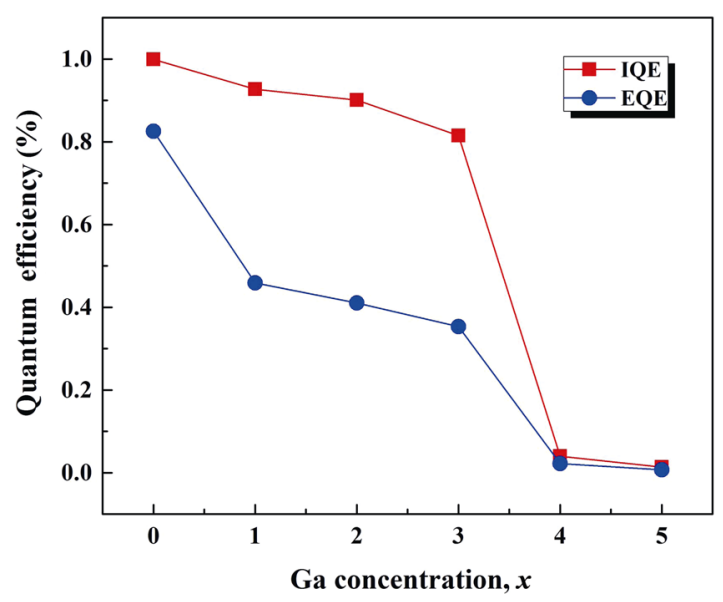

Fig. 8 Quantum efficiency for $\mathrm{Y}_{3} \mathrm{Al}_{5-x} \mathrm{Ga}_{x} \mathrm{O}_{12}$ : $\mathrm{Ce}(x=$ $0-5)$ ceramics.

Table 1 Color coordinates, LE, and CCT of all the ceramic packaged-LEDs

\begin{tabular}{|c|c|c|c|c|}
\hline No. & $\mathrm{Ga}^{3+}$ concentration & Color coordinates $(x, y$ & ) LE $(1 \mathrm{~m} / \mathrm{W})$ & $\mathrm{CCT}(\mathrm{K})$ \\
\hline 1 & $x=0$ & $(0.3994,0.4477)$ & 124.48 & 3982 \\
\hline 2 & $x=1$ & $(0.3477,0.4458)$ & 74.82 & 5160 \\
\hline 3 & $x=2$ & $(0.3037,0.4535)$ & 74.93 & 6216 \\
\hline 4 & $x=3$ & $(0.2933,0.4356)$ & 30.89 & 6691 \\
\hline 5 & $x=4$ & $(0.1399,0.0672)$ & 6.89 & out \\
\hline 6 & $x=5$ & $(0.1363,0.0573)$ & 5.61 & out \\
\hline
\end{tabular}
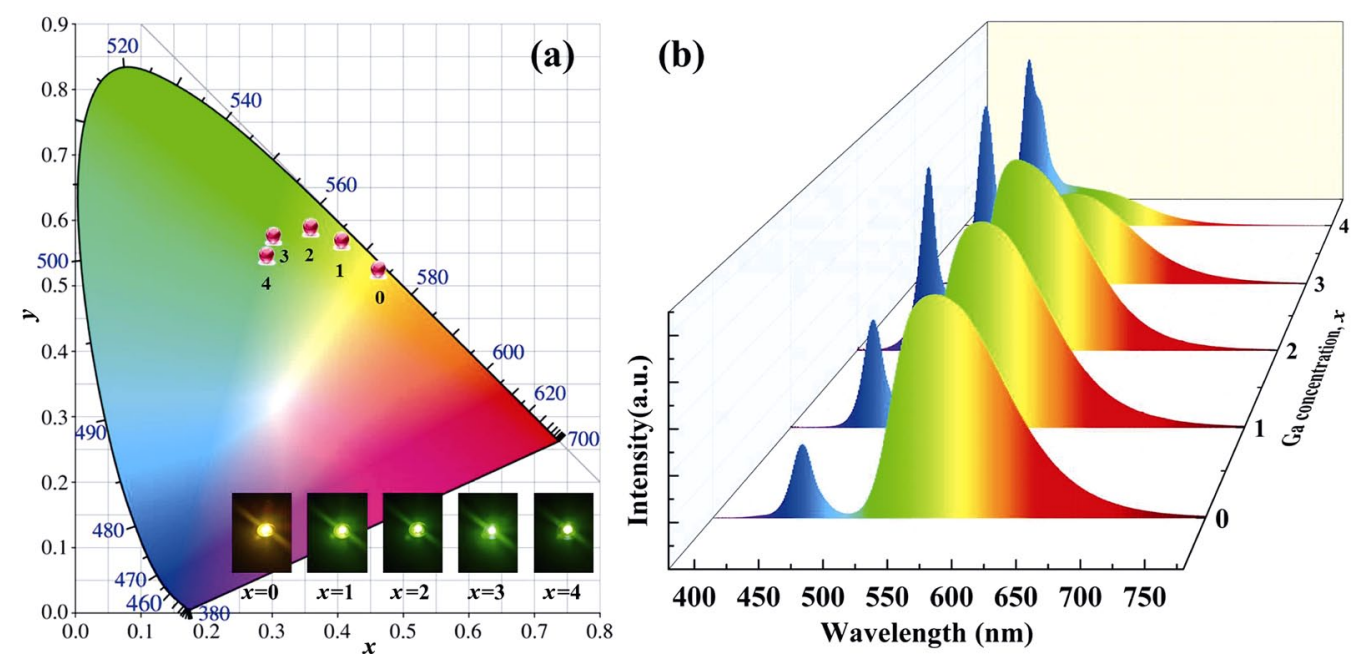

Fig. 9 (a) Chromaticity color coordinates of LEDs encapsulated with YAGG:Ce ceramics. Inset: pictures of the blue LED chip encapsulated with $\mathrm{Y}_{3} \mathrm{Al}_{5-x} \mathrm{Ga}_{x} \mathrm{O}_{12}$ : $\mathrm{Ce}(x=0-4)$ ceramics in operation (from left to right). (b) Spectra of LEDs encapsulated with YAGG:Ce ceramics. 
blue component of combined LED chip. It can be seen that the color coordinates of ceramics move towards the green light region as Ga content increases. Insets on the bottom of Fig. 9(a) are pictures of luminescence performance of different ceramics. YAG ceramic emitted yellow light, while high quality green light was obtained by coupling the YAGG:Ce ceramics with commercial blue LED chips. It can be seen from Fig. 9(b) that the intensity of blue portion increases with $\mathrm{Ga}$ content increasing, owing to the internal scattering of ceramics, which causes the weakening of the ability to absorb blue light. As a result, the proportion of the transmitted blue light increases. While the proportion of green light gradually increases as Ga concentration increases, which is consistent with Fig. 7(b). When Ga concentration is high, the PL intensity is weak and the luminescence intensity of LED device also decreases.

The temperature-dependent luminescence intensity of YAGG:Ce $(x=0-5)$ ceramics was measured in the temperature range of $25-200{ }^{\circ} \mathrm{C}$. The results are shown in Fig. 10. Luminescence intensity of all samples decreases as the temperature rises. When $x=0$, $1,2,3,4$, the luminescence intensity of YAGG:Ce ceramics at $150{ }^{\circ} \mathrm{C}$ is $93.6 \%, 90.7 \%, 83.6 \%, 19.1 \%$, and $9.4 \%$ of their intensity measured at $25{ }^{\circ} \mathrm{C}$, which indicates that YAGG:Ce ceramics have good thermal stability when Ga concentration is less than $60 \%$.

\section{Conclusions}

YAGG:Ce transparent ceramics can be prepared via a two-step sintering technique. Especially, $\mathrm{Y}_{3} \mathrm{Ga}_{5} \mathrm{O}_{12}$ (YGG)

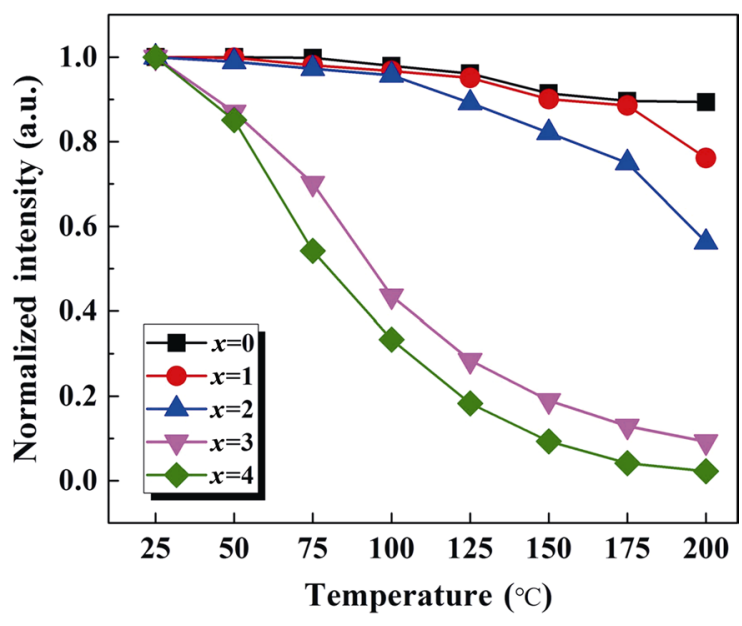

Fig. 10 Temperature-dependent luminescence intensity of $\mathrm{Y}_{3} \mathrm{Al}_{5-x} \mathrm{Ga}_{x} \mathrm{O}_{12}: \mathrm{Ce}(x=0-4)$ ceramics. transparent ceramic was successfully prepared for the first time, which was demonstrated to be a potential ceramic matrix for exploration of novel luminescent materials. The effects of Ga concentration on the crystal structure, morphology, energy level structure, and optical property of YAGG:Ce ceramics were intensively investigated. According to the first-principles calculation and Rietveld refinements, when Ga substitutes Al sites, the tetrahedral site is more favorable than the octahedral site to occupy. As Ga concentration increased, its grain size increased and a continuous blue shift of the emission from 565 to $515 \mathrm{~nm}$ can be achieved. It can be seen from the chromaticity color coordinates that the colors of samples transfer from warm yellow region to green region. High quality green light was obtained by coupling the YAGG:Ce ceramics with commercial blue LED chips. Transparent luminescence ceramics accomplished in this work can be quite prospective for high power LED application.

\section{Acknowledgements}

This research was supported by the National Key R \& D Program of China (2016YFC0101800), National Natural Science Foundation of China (51672286, U1832159, 51772185), and Science and Technology Major Project of Ningbo Municipality (2017C110028).

\section{Electronic Supplementary Material}

Supplementary material is available in the online version of this article at https://doi.org/10.1007/s40145-019-0321-9.

\section{References}

[1] Nakamura S, Mukai T, Senoh M. Candela-class highbrightness InGaN/AlGaN double-heterostructure blue-lightemitting diodes. Appl Phys Lett 1994, 64: 1687-1689.

[2] Narendran N, Gu Y. Life of LED-based white light sources. J Disp Technol 2005, 1: 167-171.

[3] Pimputkar S, Speck JS, DenBaars SP, et al. Prospects for LED lighting. Nat Photon 2009, 3: 180-182.

[4] Schubert EF. Solid-state light sources getting smart. Science 2005, 308: 1274-1278.

[5] Blasse G, Bril A. A new phosphor for flying-spot cathode-ray tubes for color television: yellow-emitting $\mathrm{Y}_{3} \mathrm{Al}_{5} \mathrm{O}_{12}-\mathrm{Ce}^{3+}$. Appl Phys Lett 1967, 11: 53-55.

[6] Bando K, Sakano K, Noguchi Y, et al. Development of high-bright and pure-white LED lamps. $J$ Light Vis Environ 1998, 22: 2-5. 
[7] Yamada M, Naitou T, Izuno K, et al. Red-enhanced white-light-emitting diode using a new red phosphor. Jpn $J$ Appl Phys 2003, 42: L20-L23.

[8] Kottaisamy M, Thiyagarajan $\mathrm{P}$, Mishra J, et al. Color tuning of $\mathrm{Y}_{3} \mathrm{Al}_{5} \mathrm{O}_{12}$ : Ce phosphor and their blend for white LEDs. Mater Res Bull 2008, 43: 1657-1663.

[9] Lee JS, Arunkumar P, Kim S, et al. Smart design to resolve spectral overlapping of phosphor-in-glass for high-powered remote-type white light-emitting devices. Opt Lett 2014, 39: 762-765.

[10] Lin YC, Karlsson M, Bettinelli M. Inorganic phosphor materials for lighting. Top Curr Chem (Z) 2016, 374: 21.

[11] Song JM, Park JS, Nahm S. Luminescence properties of $\mathrm{Eu}^{2+}$ activated $\mathrm{Ba}_{2} \mathrm{Si}_{5} \mathrm{~N}_{8}$ red phosphors with various $\mathrm{Eu}^{2+}$ contents. Ceram Int 2013, 39: 2845-2850.

[12] Xie RJ, Hirosaki N, Suehiro T, et al. A simple, efficient synthetic route to $\mathrm{Sr}_{2} \mathrm{Si}_{5} \mathrm{~N}_{8}$ : $\mathrm{Eu}^{2+}$-based red phosphors for white light-emitting diodes. Chem Mater 2006, 18: 5578-5583.

[13] Uheda K, Hirosaki N, Yamamoto H. Host lattice materials in the system $\mathrm{Ca}_{3} \mathrm{~N}_{2}-\mathrm{AlN}-\mathrm{Si}_{3} \mathrm{~N}_{4}$ for white light emitting diode. Phys Stat Sol (a) 2006, 203: 2712-2717.

[14] Li PL, Pang LB, Wang ZJ, et al. Luminescent characteristics of $\mathrm{LiBaBO}_{3}: \mathrm{Tb}^{3+}$ green phosphor for white LED. J Alloys Compd 2009, 478: 813-815.

[15] Kim HT, Kim JH, Lee JK, et al. Green light-emitting $\mathrm{Lu}_{3} \mathrm{Al}_{5} \mathrm{O}_{12}$ : Ce phosphor powders prepared by spray pyrolysis. Mater Res Bull 2012, 47: 1428-1431.

[16] Liu YH, Hao JH, Zhuang WD, et al. Structural and luminescent properties of gel-combustion synthesized green-emitting $\mathrm{Ca}_{3} \mathrm{Sc}_{2} \mathrm{Si}_{3} \mathrm{O}_{12}: \mathrm{Ce}^{3+}$ phosphor for solid-state lighting. J Phys D: Appl Phys 2009, 42: 245102.

[17] Zhang X, Zhang J, Wang R, et al. Photo-physical behaviors of efficient green phosphor $\mathrm{Ba}_{2} \mathrm{MgSi}_{2} \mathrm{O}_{7}: \mathrm{Eu}^{2+}$ and its application in light-emitting diodes. J Am Ceram Soc 2010, 93: $1368-1371$.

[18] Wang CY, Xie RJ, Li FZ, et al. Thermal degradation of the green-emitting $\mathrm{SrSi}_{2} \mathrm{O}_{2} \mathrm{~N}_{2}$ : $\mathrm{Eu}^{2+}$ phosphor for solid state lighting. J Mater Chem C 2014, 2: 2735-2742.

[19] Ratnam BV, Jayasimhadri M, Bhaskar Kumar G, et al. Synthesis and luminescent features of $\mathrm{NaCaPO}_{4}: \mathrm{Tb}^{3+}$ green phosphor for near UV-based LEDs. J Alloys Compd 2013, 564: 100-104.

[20] Li YQ, de With G, Hintzen HT. Luminescence of a new class of UV-blue-emitting phosphors $\mathrm{MSi}_{2} \mathrm{O}_{2-\delta} \mathrm{N}_{2+2 / 38}$. $\mathrm{Ce}^{3+}(\mathrm{M}=\mathrm{Ca}, \mathrm{Sr}, \mathrm{Ba}) . J$ Mater Chem 2005, 15: 4492.

[21] Shixiu C, Tao H, Mingjing TU. Research progress of green phosphor for white light emitting diodes. Mater Rev 2011, 25: $65-71$.

[22] Wei N, Lu TC, Li F, et al. Transparent Ce: $\mathrm{Y}_{3} \mathrm{Al}_{5} \mathrm{O}_{12}$ ceramic phosphors for white light-emitting diodes. Appl Phys Lett 2012, 101: 061902.

[23] Goldstein A, Krell A. Transparent ceramics at 50: Progress made and further prospects. J Am Ceram Soc 2016, 99: 3173-3197.
[24] Wang SF, Zhang J, Luo DW, et al. Transparent ceramics: Processing, materials and applications. Prog Solid State Chem 2013, 41: 20-54.

[25] Yu YP, Wang HH, Li LK, et al. Effects of various fluxes on the morphology and optical properties of $\mathrm{Lu}_{3-x} \mathrm{Al}_{5} \mathrm{O}_{12}$ : $x \mathrm{Ce}^{3+}$ green phosphors. Ceram Int 2014, 40: 14171-14175.

[26] Dorenbos P. Electronic structure and optical properties of the lanthanide activated $\mathrm{RE}_{3}\left(\mathrm{Al}_{1-x} \mathrm{Ga}_{x}\right)_{5} \mathrm{O}_{12}(\mathrm{RE}=\mathrm{Gd}, \mathrm{Y}, \mathrm{Lu})$ garnet compounds. J Lumin 2013, 134: 310-318.

[27] Mori M, Xu J, Okada G, et al. Scintillation and optical properties of Ce-doped YAGG transparent ceramics. J Rare Earths 2016, 34: 763-768.

[28] Ueda J. Analysis of optoelectronic properties and development of new persistent phosphor in $\mathrm{Ce}^{3+}$-doped garnet ceramics. J Ceram Soc Jpn 2015, 123: 1059-1064.

[29] Xu J, Ueda J, Tanabe S. Novel persistent phosphors of lanthanide-chromium co-doped yttrium aluminum gallium garnet: Design concept with vacuum referred binding energy diagram. J Mater Chem C 2016, 4: 4380-4386.

[30] Giesting PA, Hofmeister AM. Thermal conductivity of disordered garnets from infrared spectroscopy. Phys Rev B 2002, 65: 144305.

[31] Chen XQ, Qin HM, Zhang Y, et al. Preparation and optical properties of transparent $(\mathrm{Ce}, \mathrm{Gd})_{3} \mathrm{Al}_{3} \mathrm{Ga}_{2} \mathrm{O}_{12}$ ceramics. $J$ Am Ceram Soc 2015, 98: 2352-2356.

[32] Yoshikawa A, Fujimoto Y, Yamaji A, et al. Crystal growth and characterization of $\mathrm{Ce}: \mathrm{Gd}_{3}(\mathrm{Ga}, \mathrm{Al})_{5} \mathrm{O}_{12}$ single crystal using floating zone method in different $\mathrm{O}_{2}$ partial pressure. Opt Mater 2013, 35: 1882-1886.

[33] Perdew JP, Burke K, Ernzerhof M. Generalized gradient approximation made simple. Phys Rev Lett 1996, 77: 3865-3868.

[34] Kresse G, Furthmüller J. Efficient iterative schemes forab initiototal-energy calculations using a plane-wave basis set. Phys Rev B 1996, 54: 11169-11186.

[35] Kresse G, Hafner J. Ab initio molecular dynamics for open-shell transition metals. Phys Rev B 1993, 48: 13115-13118.

[36] Shannon RD, Prewitt CT. Effective ionic radii in oxides and fluorides. Acta Crystallogr Sect B 1969, 25: 925-946.

[37] Krogh-Moe J. Refinement of the crystal structure of caesium triborate, $\mathrm{Cs}_{2} \mathrm{O}_{3} \mathrm{~B}_{2} \mathrm{O}_{3}$. Acta Crystallogr Sect B 1974, 30: 1178-1180.

[38] Seijo L, Barandiarán Z. $4 f$ and $5 d$ Levels of $\mathrm{Ce}^{3+}$ in $D_{2}$ 8-fold oxygen coordination. Opt Mater 2013, 35: 1932 1940.

[39] Muñoz-García AB, Seijo L. Structural, electronic, and spectroscopic effects of Ga codoping on Ce-doped yttrium aluminum garnet: First-principles study. Phys Rev B 2010, 82: 184118.

[40] Marezio M, Remeika JP, Dernier PD. Cation distribution in $\mathrm{Y}_{3} \mathrm{~A}_{15-c} \mathrm{Ga}_{c} \mathrm{O}_{12}$ garnet. Acta Crystallogr Sect B 1968, 24: 1670-1674.

[41] Vrubel II, Polozkov RG, Shelykh IA, et al. Bandgap engineering in Yttrium-Aluminum garnet with Ga doping. 
Cryst Growth Des 2017, 17: 1863-1869.

[42] Chewpraditkul W, Pánek D, Brůža P, et al. Luminescence properties and scintillation response in $\mathrm{Ce}^{3+}$-doped $\mathrm{Y}_{2} \mathrm{Gd}_{1} \mathrm{Al}_{5-x} \mathrm{Ga}_{x} \mathrm{O}_{12}(x=2,3,4)$ single crystals. J Appl Phys 2014, 116: 083505.

[43] Ogiegło JM, Katelnikovas A, Zych A, et al. Luminescence and luminescence quenching in $\mathrm{Gd}_{3}(\mathrm{Ga}, \mathrm{Al})_{5} \mathrm{O}_{12}$ scintillators doped with $\mathrm{Ce}^{3+}$. J Phys Chem A 2013, 117: 2479-2484.

[44] Holloway WW, Kestigian M. Optical properties of ceriumactivated garnet crystals. J Opt Soc Am 1969, 59: 60-63.

Open Access This article is licensed under a Creative Commons Attribution 4.0 International License, which permits use, sharing, adaptation, distribution and reproduction in any medium or format, as long as you give appropriate credit to the original author(s) and the source, provide a link to the Creative Commons licence, and indicate if changes were made.

The images or other third party material in this article are included in the article's Creative Commons licence, unless indicated otherwise in a credit line to the material. If material is not included in the article's Creative Commons licence and your intended use is not permitted by statutory regulation or exceeds the permitted use, you will need to obtain permission directly from the copyright holder.

To view a copy of this licence, visit http://creativecommons. org/licenses/by/4.0/. 